\title{
HEXADACTYLY IN ALL FOUR LIMBS IN A NEONATE - A CASE REPORT
}

\author{
BANERJEE $\mathrm{M}^{1}$, MAJUMDAR SK ${ }^{2}$
}

\begin{abstract}
:
Polydactyly or hyperdactyly is a congenital physical anomaly and is a common congenital digital variation affecting the hand and foot. It may present as a range of defects from minor soft tissue duplications to major bony abnormalities. Of the different varieties the post-axial one is the commonest. Polydactyly may appear as isolated or in association with other birth defects. For proper management a comprehensive knowledge of this condition is required for medical experts particularly the pediatric orthopedic surgeons. Here we report a case of hexadactyly (six fingers) in all four limbs of a neonate. This neonate was free from other congenital anomaly. Photograph and radiographs revealed the anatomical abnormalities, which is essential for proper planning of the future management.
\end{abstract}

Key words: Polydactyly, congenital anomaly.

J Dhaka Med Coll. 2013; 22(2) : 219-222.

\section{Introduction:}

Polydactyly or polydactylism [from ancient Greek (polus) many + (daktulos) finger] also known as hyperdactyly is a congenital physical anomaly in human. Polydactyly literally means "extra digits". There may be an extra thumb, small finger or less commonly an extra digit in the central part of hand. When both the hands and feet have six digits each the condition is called Hexapolydactyly. Bergania and Temtanw classified polydactyly into preaxial, central, and postaxial types ${ }^{1}$. Radial or preaxial polydactyly means there is an extra thumb or duplication of the first digit or ray. There are several different types of radial polydactyly. Ulnar or post axial polydactyl means that there is an extra small finger attached to the little finger that is duplication of fifth digit or ray. There may be a well formed extra small finger or just a poorly formed extra digit attached by a thin stalk of soft tissue. Central polydactyly means that the extra digit is in the central part of the hand between the thumb and small finger. It involves duplication of the second, third, or fourth digit or ray. Similarly the term tibial, central, fibular have been proposed to describe polydactyly in the lower extremity. Even rarer is crossed polydactyly, where pre axial involvement of one extremity is coupled with post-axial involvement of the opposite end of the body. Polysyndactyly is the combination of polydactyly and syndactyly .

Five types of polydactyly are encountered, Type I- Cutaneous nubbin, Type II- Pedunculated digit, Type III- Articulating digit with fifth metacarpal , Type IV- Fully developed digit with fifth metacarpal, and Type V- Polysyndactyly. Type I and II ulnar polydactyly are more common ${ }^{2}$.

During normal embryonic development, the hand initially forms in the shape of a paddle and then eventually splits into separate fingers. Polydactyly results if there is an error in this process and an extra finger forms where a single finger splits in to two ${ }^{3}$. Many times, the condition occurs without any apparent cause, while some may be due to a genetic defect. It can also happen as a part of an under lying hereditary syndrome and can pass down generation to generation ${ }^{4}$. Polydactyly does not generally pose any health risk over time. Surgery is indicated to improve cosmoses and to improve shoe-fit. It is usually performed when the patient is aged approximately 1 year of age, so the effect of development and walking

1. Dr.Manisha Banerjee, Associate Professor, Department of Neonatology, Dhaka Medical College, Dhaka.

2. Dr. Sajal Kumar Majumdar, Associate Professor, Department of Paediatric Surgery, Shaheed Suhrawardy Medical College, Dhaka.

Correspondence : Dr.Manisha Banerjee, Associate Professor, Department of Neonatology, Dhaka Medical College, Dhaka. 
is minimal. Surgery delayed past early child hood is less likely to give satisfactory result. Though surgery should be delayed till skeletal development (ossification) has occurred within the affected rays so that accurate anatomic assessment is possible ${ }^{5}$. Surgical intervention in polydactyly are indicated for various regions. To have a successful surgical procedure detailed knowledge regarding the bony architecture of the region is necessary. We here present a neonate of 7 days old with six separate metacarpal and six digits in both hands and six separate meta- tarsal and six digits in both foot.

\section{Case Report:}

A 7 days old male baby appropriate for gestational age, only issue of his consanguineous parents was born in a local clinic by lower uterine cesarean section due to leaking membrane for 12 hours. Mother of the baby did not give any significant illness during her pregnancy period.

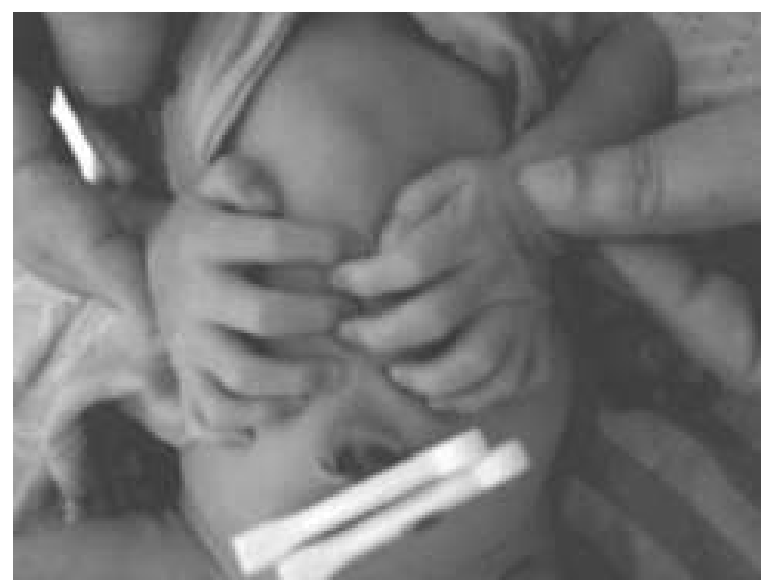

Fig.-1: Hexadactyly in hands.

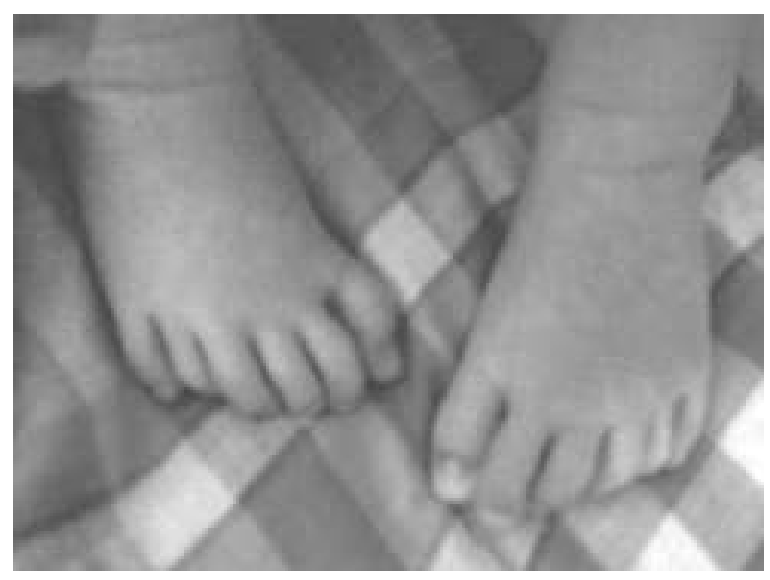

Fig.2: Hexadactyly in feet.
On examination the baby weighed 2650 grams with a length of $48 \mathrm{~cm}$ and had head circumference of $35 \mathrm{~cm}$. The boy had six fingers each in all his four limbs. The extra fingers were postaxial type, on the ulnar side of the upper limb while on the fibular side in the lower limb. The dermatologiphic pattern of limbs was normal. The baby could move all the extra fingers of his limbs by himself. All the fingers were well formed. On palpation there were bony elements in each digit with mobile joints. The number and the pattern of his carpal and tarsal bones could not be ascertained due to his tender age. All the other joints of his limbs appeared to be normal.

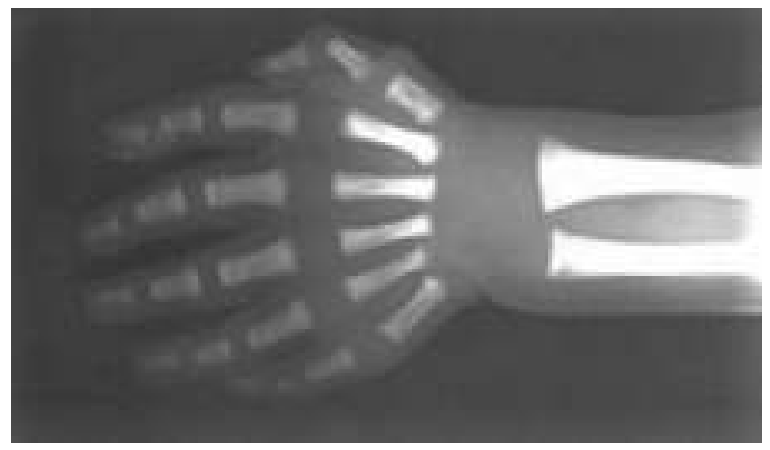

$X$-ray showing hexadactyly in left hand.

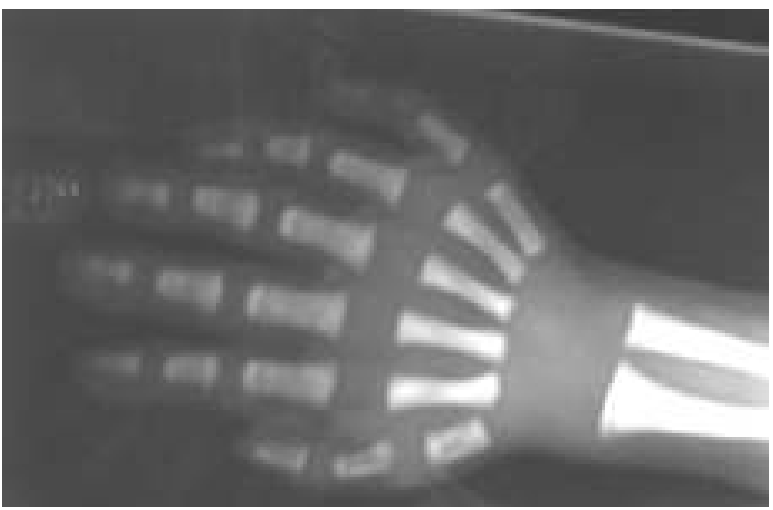

$X$-ray showing hexadactyly in right hand.

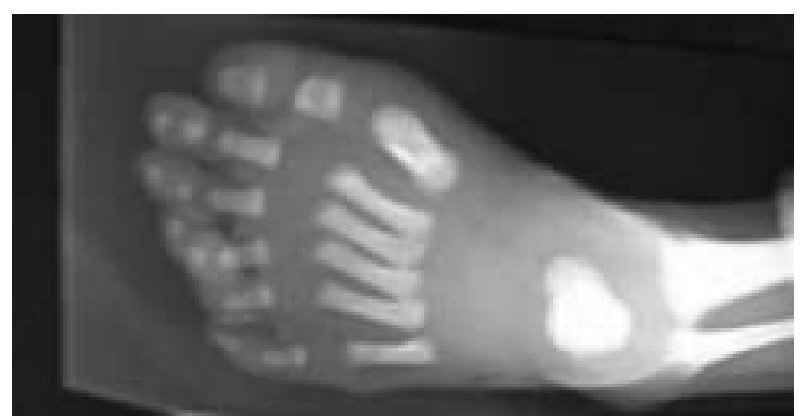

$X$-ray showing hexadactyly in left foot 


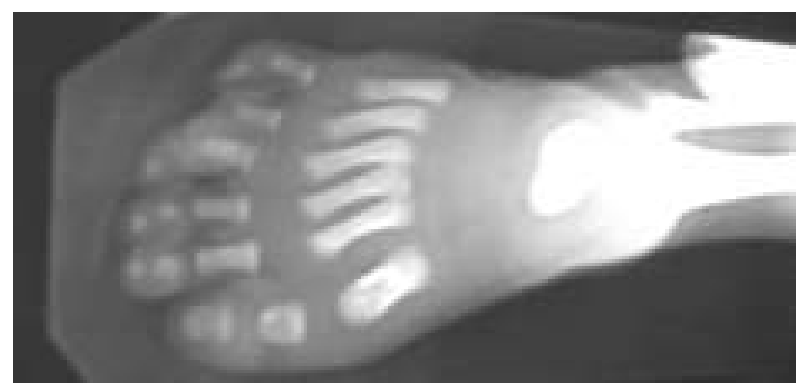

$X$-ray showing hexadactyly in right foot

Radiographs of both feet and hands were taken with the written consent from parents explaining the reason behind. It revealed bilateral symmetrical bony appearance of both the hands and also feet. The boy had no abnormality of his nails nor had any cleft lip and cleft palate. Echocardiography and ultrasongraphy of abdomen revealed no abnormality. Laboratory tests including hormonal studies and other biochemical tests were within normal limits. The external features did not reveal stigmata of any congenital syndrome. None of his first degree relatives had this short of variation. So this case was finally diagnosed as a case of sporadic postaxial hexadactyly in a neonate with symmetrical pattern in all four limbs. Functional limitations cannot be assessed as the baby was only 7 days old. So plan of management for polydactyly was deferred till full assessment of functional ability of these extra fingers.

\section{Discussion:}

Polydactyly is a condition of more than 5 fingers in a limb. The condition has an incidence of 1 in every 500 live births ${ }^{6}$. Postaxial hand polydactyly is a common isolated disorder in African black and African American children and autosomal dominant transmission is suspected ${ }^{7}$. Postaxial polydactyly is approximately 10 times more frequent in blacks than in whites and is more frequent in male child ${ }^{7}$. In contrast, postaxial polydactyly seen in white children is usually syndromic and associated with an autosomal recessive transmission. All types of polydactyly is more common in males than female and related to consanguinity ${ }^{6}$. Our case was unique in that the neonate had six well formed separate metacarpals in each hand and metatarsals in his each foot. The phalanges are well formed, each articulating separately with individual metacarpal and toes with their respective metatarsal. All the joints appeared to be well formed and functional.

Polydactyly should not be considered as a single mendelian trait but rather multifactorial ${ }^{8}$. Early theories for polydactylyty concerned disorders in the programmed cell death cycle of fetal limb development ${ }^{4}$. Current theories focus on mutation in specific genetic locations that causes limb development to go awry. Mammals have been shown to have genetic clusters identified as homeobox or hoxgenes corresponding to 5 domains across the limb buds $^{8}$. According to Rittler $\mathrm{M}$ et al mutations in the Hox D 13 gene are associated with synpolydactyly. Recently another locus on chromosome 19p 13.1-13.2 is found to be associated $^{9}$.

Syndromes including polydactyly include Meckel syndrome, Smith-hemli-opitiz syndrome, Jeune syndrome, short ribpolydactyly syndrome, Ellis-van creveld syndrome, Ectrodactyly-ectodermal dysplasiacleft lip/palate syndrome, Bardet-Biedl (Type 2 $\& 3$ ) and Trisomy(13-15). Down syndrome was associated strongly with duplication of the first $\operatorname{digit}^{10}$.

Surgical correction of polydactyly is attempted for cosmetic region, to relieve pain if any and to have properly fitted shoes. A pre-surgical radiograph, followed by amputation of the accessory digit and excision of the extra bony part is the standard practice. A flail, poorly attached appendages should be amputed early. Operative correction of preaxial polydactyly is sometimes delayed until 12 months of age, when functional evaluation is possible and the dominant (usually) ulnar thumb can be identified and preserved. The collateral ligaments, even tendons and bony elements of the ablated digit are salvaged for reconstruction of the remained digit. The type of deformity, type of procedure and skillfulness of the surgeon play a major role in the success of the surgery $^{2}$. As our case was a newborn of 7 days old we decided to wait till the baby grow up to assess the functional integrity of joint of hands 
and feet as well as cosmetic look of hands and feet and any discomfort with shoes.

\section{References:}

1. Bergania D, Temtanw SA. Polydactyly. BMJ 2000; 32(1): 23-30.

2. Rayen GM, Fray B. Ulnar Polydactyly. Plast Reconstr Surg 2001; 107(6): 1449-54.

3. Daluiski A, Yi SE, Lyons KM. Molecular control of upper extremity development. J Hand Surg 2001; 26(1): 8-22.

4. Beaty JH. Congenital Anomalies of lower extremity. In: Cannel ST, Campbel WC editors. Campbell's operative orthopedics. $10^{\text {th }}$ Ed., St. Louuis: Mosby; 2003. p.973-5.

5. Ogino T, Ishii S, Takahata S, Kato H. Long term results of surgical treatment of thumb polydactyly. J Hand Surg 1996; 21: 478-88.
6. Mukurjee S, Paul R, Bandyopadhay M, Das P. Post axial polydactyly in four limbs with different bony configurations. Int $\mathrm{J}$ Anat Variations 2011; 4: 77-9.

7. Chakraborty PB, Marjit B, Dutta S, Dey A. Polydactyly: a case study. J Anat Soc India 2007; 659(1): 01-6.

8. Zhao H, Tian Y, Breedveld G, Huang S, Zoo Y, Chai J, et al. Poxtaxial polydactyly type A/B (PAPA/B) is linked to chromosome 19q13.1-13.2 in a Chinese kinderd. Eur J Ham Genet 2002; 10: 162-6.

9. Rittler M, Liascovich R, Lopez-Camelo J, Castilla EE. Parental Consanguinity in specific types of congenital anomalies. Am J Med Genet 2001; 102(1): 36-43.

10. Miranda EP, Mathes SJ. Congenital defects of the skin, connective tissue, muscles tendons and hands. In: Grosfeld JL, O'Neill JA, Coran AG, Fonkalsrud EW eds. Paediatric Surgery. vol-2, $6^{\text {th }}$ ed. St. Louis: Mosby Elsevier; 2006. p.2061-78. 